PREPARED FOR THE U.S. DEPARTMENT OF ENERGY, UNDER CONTRACT DE-AC02-76CH03073

PPPL-3796

PPPL-3796

UC-70

Preliminary Results of Plasma Flow Measurements in a $2 \mathrm{~kW}$ Segmented Hall Thruster

by

Y. Raitses, D. Staack, A. Dunaevsky, L. Dorf, and N.J. Fisch

March 2003

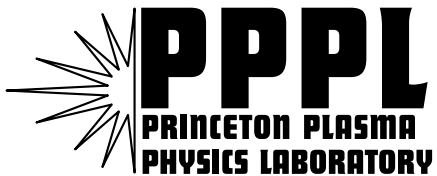

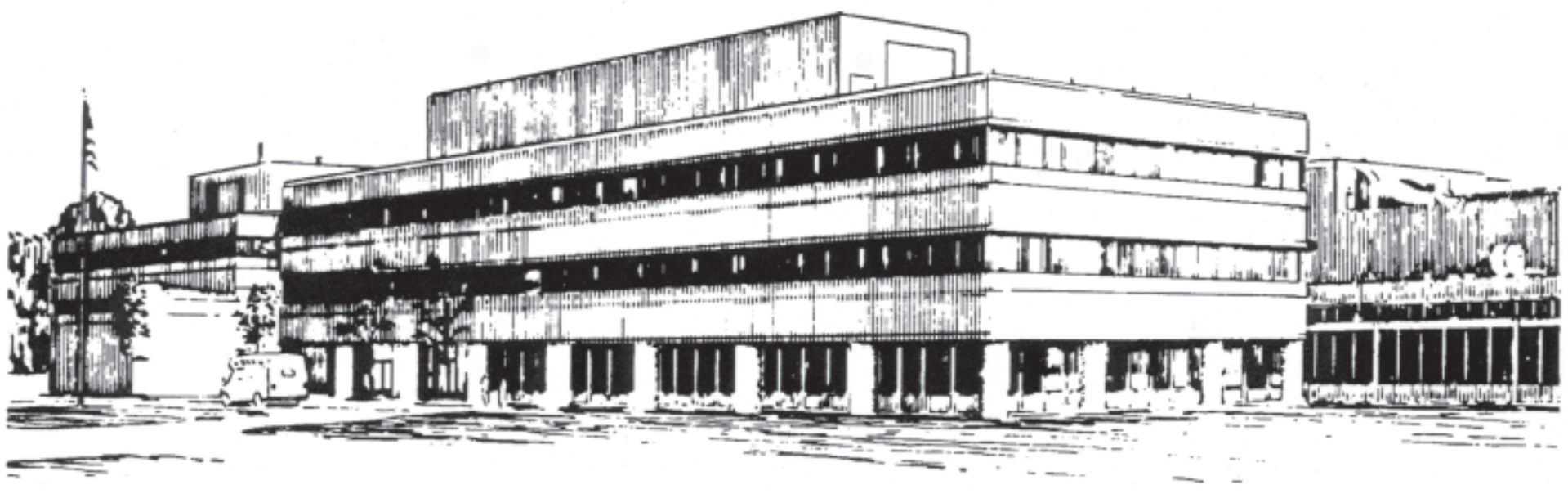

PRINCETON PLASMA PHYSICS LABORATORY PRINCETON UNIVERSITY, PRINCETON, NEW JERSEY 


\section{PPPL Reports Disclaimer}

This report was prepared as an account of work sponsored by an agency of the United States Government. Neither the United States Government nor any agency thereof, nor any of their employees, makes any warranty, express or implied, or assumes any legal liability or responsibility for the accuracy, completeness, or usefulness of any information, apparatus, product, or process disclosed, or represents that its use would not infringe privately owned rights. Reference herein to any specific commercial product, process, or service by trade name, trademark, manufacturer, or otherwise, does not necessarily constitute or imply its endorsement, recommendation, or favoring by the United States Government or any agency thereof. The views and opinions of authors expressed herein do not necessarily state or reflect those of the United States Government or any agency thereof.

\section{Availability}

This report is posted on the U.S. Department of Energy's Princeton Plasma Physics Laboratory Publications and Reports web site in Fiscal Year 2003. The home page for PPPL Reports and Publications is: http://www.pppl.gov/pub_report/

DOE and DOE Contractors can obtain copies of this report from:

U.S. Department of Energy

Office of Scientific and Technical Information

DOE Technical Information Services (DTIS)

P.O. Box 62

Oak Ridge, TN 37831

Telephone: (865) 576-8401

Fax: (865) 576-5728

Email: reports@adonis.osti.gov

This report is available to the general public from:

National Technical Information Service

U.S. Department of Commerce

5285 Port Royal Road

Springfield, VA 22161

Telephone: $1-800-553-6847$ or

(703) $605-6000$

Fax: (703) 321-8547

Internet: http://www.ntis.gov/ordering.htm 


\title{
PRELIMINARY RESULTS OF PLASMA FLOW MEASUREMENTS IN A 2 KW SEGMENTED HALL THRUSTER
}

\author{
Y. Raitses, D. Staack, A. Dunaevsky, L. Dorf and N. J. Fisch \\ Princeton University Plasma Physics Laboratory, Princeton, NJ 08543
}

\begin{abstract}
A $2 \mathrm{~kW}$ Hall thruster was developed, built and operated in an upgraded vacuum facility. The thruster performance and parameters of the plasma flow were measured by new diagnostics for plume measurements and plasma measurements inside the thruster channel. The thruster demonstrated efficient operation in terms of propellant and current utilization efficiencies in the input power range of 0.5-3.5 kW. Preliminary measurements of the ion energy spectra from the thruster axis region and the distribution of plasma parameters in the vicinity of the thruster exit are reported.
\end{abstract}

\section{INTRODUCTION}

The use of emissive and non-emissive conductive electrodes and dielectric spacers placed in the Hall thruster channel can potentially help to control the plasma flow. ${ }^{1,2,3}$ Such control can be useful in order to maintain a narrow plasma jet from the thruster, provide high ionization efficiency for variable thrust operating regimes and allow for a longer thruster lifetime. This may be important for high power Hall thrusters $(>10 \mathrm{~kW})$ with typically wider channels than their sub-kilowatt and kilowatt counterparts. ${ }^{4,5}$ In these large thrusters the acceleration region may be established outside of the channel in the defocusing fringing magnetic field possibly leading to larger plume angles of the plasma jet. Magnetic fields can be configured to optimize low and moderate input power Hall thrusters, but this optimization tool may reach its fundamental limits and become ineffective for large thrusters.

In our previous work we demonstrated that segmented electrodes can significantly reduce voltage potential drop outside the channel and establish a favorable shape of equipotentials to reduce the plume angle as compared to non-segmented thruster configuration. ${ }^{3,6,7}$ This study was performed on a $9 \mathrm{~cm}$ laboratory Hall thruster, which was operated in a sub-kilowatt input power range inside a $28 \mathrm{~m}^{3}$ vacuum vessel equipped with a diffusion pump. The plume characteristics, namely, ion flux and plume angle for $90 \%$ of the total ion flux were measured by an electrostatic Langmuir probe with a guarding sleeve at the distance of $33 \mathrm{~cm}$ from the thruster exit. Since the background pressure was above $3 \cdot 10^{-5}$ torr facility effects could affect those measurements. ${ }^{8}$ Therefore, our primary approach was a comparison of different segmented and non-segmented thruster configurations at the same gas flow rate and discharge voltage. Besides plume measurements, a fast movable emissive probe and a double probe measured the plasma potential distribution and electron temperature. Although these measurements were typically accompanied by significant probe induced perturbations of the plasma, a reasonable comparison of different thruster configurations was possible in the relatively quiet thruster regions outside and near the thruster exit. In general, these exterior and interior plasma flow measurements gave us some qualitative picture of the effects of segmented electrodes on the thruster operation. A comparison of measured and theoretical results suggested that these effects might be attributed to plasma-wall interactions, and may be partially explained by the ion collecting role, secondary electron emission and conductivity of the electrode materials. ${ }^{3,9}$ However, there is still a strong need to precisely understand these effects and their dependence on the thruster operation and geometry. For this purpose, more accurate and detailed measurements of the plasma flow under various operating conditions and different electrode and channel configurations and materials are necessary.

In this paper, we present preliminary results of integral and local measurements for a new $2 \mathrm{~kW}$ Hall thruster built specifically for studies of segmented electrode effects and their scaling. The vacuum facility at PPPL has been recently upgraded with 2 cryogenic pumps to facilitate reliable thruster experiments in the designed power range. Measurements inside and outside the thruster were conducted with new and upgraded plasma diagnostics. 


\section{TEST FACILITY AND THRUSTER}

\section{Vacuum facility}

All thruster experiments were conducted in a $2.3 \mathrm{~m}$ diameter by $8.4 \mathrm{~m}$ long vacuum vessel. The stainless steel walls of the vessel, which are exposed to the plasma plume, are partially covered with a graphite foil material to protect them from sputtering. Recently upgraded vacuum system consists of two CVI cryogenic pumps: a TM 1200i is mounted internally on the back dome flange about $2 \mathrm{~m}$ behind the thruster and a 42 " diameter TMP 1000 is attached to one of two vacuum ports $3.5 \mathrm{~m}$ downstream from the thruster. A second port, which is $1.6 \mathrm{~m}$ from the thruster, can be used in the future for an additional externally mounted cryogenic pump. The base pressure and background pressure with Xenon are measured with two nude ion gauges, which are placed on two conflate flanges opposite one another $2 \mathrm{~m}$ downstream from the thruster exit. In addition, residual gases and total background pressure are monitored with a SRS residual gas analyzer RGA-300 (300 a.m.u). The base pressure was $2-3 \cdot 10^{-8}$ torr. The total measured pumping speed of two cryogenic pumps was $\approx 62,0001 / \mathrm{s}$ with xenon flow. At xenon flow rates of below $50 \mathrm{sccm}$, the background pressure was lower than $10^{-5}$ torr.

In addition to the large vacuum facility, a small $0.4 \mathrm{~m}^{3}$ vacuum chamber equipped with a $1500 \mathrm{l} / \mathrm{s}$ (for xenon) turbo-molecular pump was used for testing of thruster parts and calibration of plume diagnostics.

\section{Thruster}

A new $2 \mathrm{~kW}$ Hall thruster has a modular design and consists of a coaxial channel made from a boron nitride ceramic material, magnetic circuit, and the anode, which is also a gas distributor (Fig. 1). The channel can be made either from a solid ceramic piece or segments of different ceramic and conductive materials. The outer and inner diameters are $123 \mathrm{~mm}$ and $73 \mathrm{~mm}$, respectively. The effective channel length taken from the anode to the channel exit is $46 \mathrm{~mm}$. The thicknesses of the outer and inner walls are $6 \mathrm{~mm}$ and $4 \mathrm{~mm}$, respectively. The segmented electrodes can easily be attached to these thick walls at different locations along the thruster axis and aligned with the entire channel by using steps and grooves on their front and rear sides. A stainless steel channel holder has adjustable springs to align the channel or channel segments relative to the magnetic circuit and compensate for thermal expansion of the channel during thruster operation. The magnetic circuit includes the magnetic core, which is made from a low carbon steel, two main and two additional fine-tuning electromagnetic coils. In addition to magnetic screens, these additional coils assist in controlling the magnetic field profile in the $25 \mathrm{~mm}$ with thruster channel. The thruster was designed to provide easy access to the channel by various plasma diagnostics. For this purpose, the channel has a number of axial slots across and longitudinal bores along the outer channel wall.

Inside the vacuum vessel, the thruster is held by an adjustable frame, which is mounted on an aluminum breadboard table attached rigidly to the bottom of the vacuum vessel. Both thruster and table are electrically insulated from the vessel.

A HWPES-250 series plasma electron source by HeatWave capable of supplying up to $10 \mathrm{~A}$ of the plasma electron current is used as a cathode-neutralizer. The cathode is connected to the thruster frame through ceramic breakers and placed at $60^{\circ}$ relative to the thruster axis.

\section{Power and gas flow}

The xenon gas flow to the anode and cathode is controlled by two Millipore FC-260 flow controllers (anode $0-80 \mathrm{sccm}$ and cathode $0-10 \mathrm{sccm}$ ), which are connected to a LR-250 readout and control box. In addition to manufacturer calibration, both flow controllers were calibrated volumetrically at specific xenon flow rates used in the experiments described below. For the anode flow controller at large flow rates, the volumetric value deviated from the readout value about $4 \%$. Therefore, all flow rates below are given in accordance with results of volumetric calibrating tests.

To support the thruster operation, a $1 \mathrm{kV}-10 \mathrm{~A}$ voltage regulated switching power supply, BRC-1000 by Universal Voltronics, is used. Two PowerTen voltage regulated power supplies provide the cathode heating and discharge ignition for starting the thruster. The main discharge and cathode power supplies are floating relative to ground. The electromagnetic coils of the thruster are supplied by four separate current regulated power supplies. The two power supplies of the adjusting coils are bipolar to enable fine-tuning variations of the magnetic field distribution. 
All power supplies and gas flow readout can be controlled and monitored remotely from a PC. However, in this preliminary set of experiments only discharge current and floating potential of the cathode relative to ground were measured through isolation amplifiers by a PC based data acquisition system.

\section{Thruster operation and discharge characteristics}

The Hall thruster was operated with xenon gas in the input power range of 0.5 to $3.5 \mathrm{~kW}$. Illustrative curves of measured voltage versus current characteristics are shown in Fig. 2. For a comparison of thruster operating regimes, some of these characteristics were measured without changes of the magnetic field distribution. As can be seen, an increase of the discharge voltage at a constant mass flow rate and magnetic field leads to non- monotonic changes of the discharge current. Since no ac measurements were conducted in this set of experiments, it is not clear if these changes are associated with low frequency discharge oscillations and their dependence on the discharge voltage observed in Ref. 10. At a mass flow rate of $7 \mathrm{mg} / \mathrm{s}$, the coils currents were changed, but not optimized, to limit the discharge current and thus, to avoid overheating of the anode and other thruster parts.

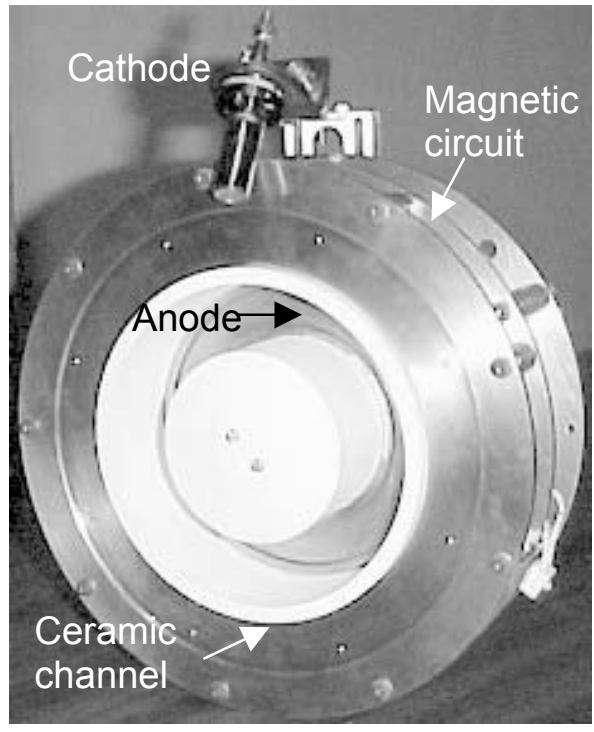

Fig. 1 New $2 \mathrm{~kW}$ Hall thruster Channel OD diameter $=123 \mathrm{~mm}$ Channel width $=25 \mathrm{~mm}$

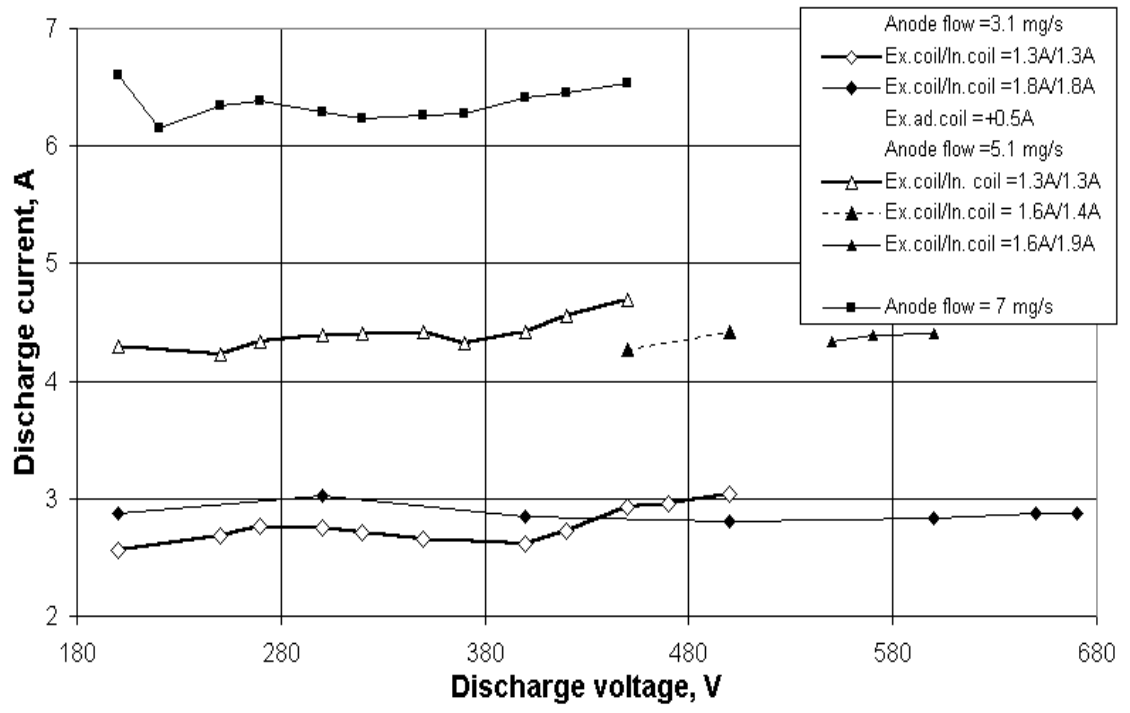

Fig. 2 V-I characteristics measured for three anode mass flow rates of xenon gas: $3.1,5.1$ and $7 \mathrm{mg} / \mathrm{s}$ and at different external and internal electromagnetic coils currents.

\section{DIAGNOSTIC SETUP}

\section{Plume measurements}

The plume diagnostics setup was upgraded with a high precision rotating system and several diagnostic tools, namely, a flat electrostatic probe with a guarding sleeve, $45^{\circ}$ two-plate energy analyzer, retarding potential analyzer, and a time-of-flight spectrometer. In the present experiments, only the flat probe and two-plate energy analyzer were used (Fig. 3). The other plume diagnostics are currently being manufactured or calibrated.

The rotating system consists of a $600 \mathrm{~mm}$ diameter aluminum disk held horizontally by three bearingstabilizers, which are placed at $120^{\circ}$ on the mounting platform (Fig. 3). A vacuum compatible Empire Magnetic stepper motor is attached rigidly to the platform and rotates the disk. This motor is driven by a Gemini GT6 digital controller, which can vary speed of the disk from 0 to $18 \mathrm{rpm}$. The axis of rotation can be adjusted relative to the thruster position. All diagnostic tools are suspended on titanium arms (Fig. 3), which are floating relative to the ground. The radius of arm rotation can be set from 500 to $1000 \mathrm{~mm}$. Up to 12 arms can be simultaneously installed on the rotating disk. Each arm is able to support up to $6 \mathrm{~kg}$. Precision adjustment of the diagnostic instruments and their orientation relative to the thruster is done by compact multi-axis movable stages. A Heidenhain ERN 620 angular optical encoder measured the actual angular position with an accuracy of $\pm 0.09^{\circ}$. The angular path for all mounted diagnostic tools is slightly less than $360^{\circ}$ because of the limiting switches. 
The plume diagnostics exposed to the plasma jet can be intensively sputtered and heated up by energetic ions. As a result, products of sputtering and outgasing can contaminate thruster parts and the cathode leading to unstable thruster operation. We tested three low sputtering carbon based materials, namely, graphite foil, graphite fabric and carbon velvet on a thin aluminum panel. Rectangular $(150 \mathrm{~mm}$ by $200 \mathrm{~mm})$ targets of these materials were attached to the supporting arms of the rotating system and separately exposed to the plasma jet at the distance of about $800 \mathrm{~mm}$. The thruster was operated at $250 \mathrm{~V}$ with xenon mass flow of $5 \mathrm{mg} / \mathrm{s}$. Only carbon velvet targets induced no changes in the thruster discharge current. In addition, RGA measurements showed that the carbon velvet produced the smallest fraction of residuals (Fig. 4). Based on these tests, carbon velvet on a flexible thin aluminum panel or foil was selected and used for the protection of all plume diagnostics.

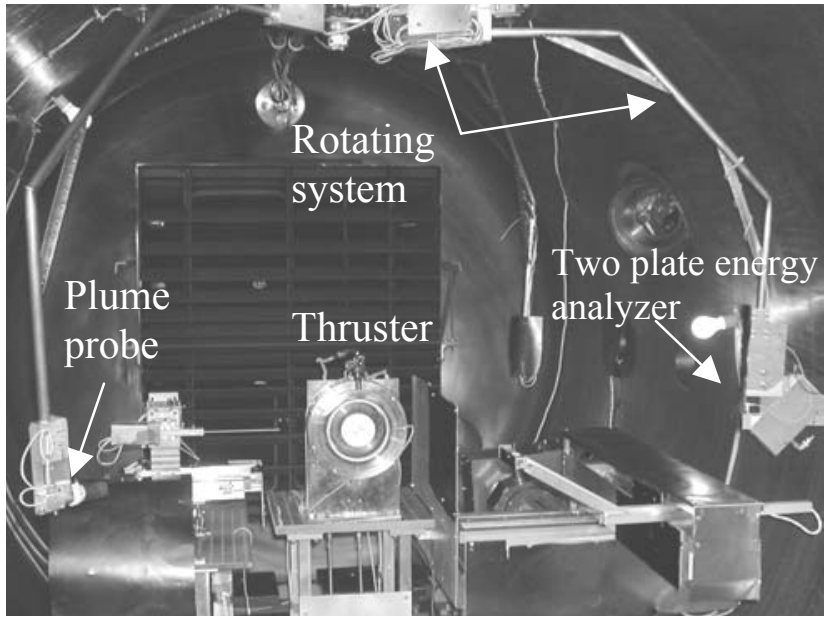

Fig. 3 The thruster, rotating system and plume diagnostics.

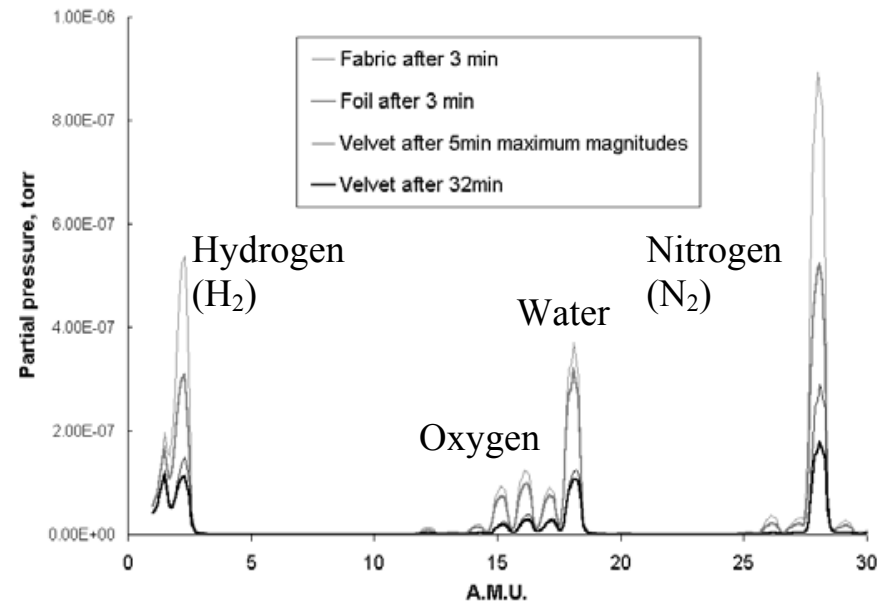

Fig. 4 RGA measurements for three sputtering resistant carbon based target materials: foil, fabric and carbon velvet on aluminum panel.

The flat electrostatic probe with a guarding sleeve is used to measure the total ion flux and plume angle for all ions coming from the thruster. Both probe and sleeve are made from a low sputtering carbon material. The probe axis is pointed to the thruster center at the exit plane. The distance between the collecting surface of the probe and the thruster exit plane, which is equal to the radius of probe rotation around the thruster center, is $730 \mathrm{~mm}$. The probe diameter is $25.4 \mathrm{~mm}$. The gap between the probe and sleeve is $0.25 \mathrm{~mm}$ that is comparable to the sheath size (for $10^{9}-10^{10} \mathrm{~cm}^{-3}, \mathrm{~T}_{\mathrm{e}} \sim 1-2 \mathrm{eV}$ ) and small enough to compensate edge effects of the probecollecting surface in the presence of the plasma.

Both probe and sleeve are biased relative to the ground from the voltage regulated power supply. The probe current is determined from the voltage drop across a $0.5 \mathrm{kOhm}$ resistor. We checked that the probe measurements were not affected by changes of the resistor in the sleeve electrical circuit from 0.1 to $1 \mathrm{kOhm}$. Measurements of the probe V-I characteristics for different flow rates and discharge voltages showed that the probe bias of $-30 \mathrm{~V}$ is sufficient to reach ion current saturation at all angular positions of the probe. Therefore, this bias voltage was applied to both probe and sleeve in all plume measurements described below.

Probe measurements were taken while the probe rotated between $\pm 90^{\circ}$ relative to the thruster axis. In order to avoid uncertainties in the placement of the rotating system relative to the thruster axis and alignment of the thruster parts, the physical centerline corresponding to a symmetrical probe current profile was defined as the zero reference angle. In the described measurements the discrepancy between the thruster axis and physical centerline was less than $3^{\circ}$.

Since probe measurements can be affected by ion neutral collisions in the plasma jet ${ }^{11}$, a separate set of experiments was conducted with the probe oriented away from the thruster in the direction of the plasma jet. In this orientation, the probe should collect only low energy ions of the background plasma. Measured results showed that a low energy flux has at least three local maximums: at the centerline of the thruster and at $\pm 90^{\circ}$ relative to the thruster axis. In each operating regime the rear faced probe maximums were comparable to the ion flux measured by the thruster facing probe at angular positions of $\pm 90^{\circ}$. This result suggests at these limiting positions the probe collects ions mainly from the background plasma, which offsets the probe measurements. 
Therefore, in order to reduce uncertainties in determination of the total ion flux, the ion current measured by the probe at $90^{\circ}$ was subtracted from measurements at the other angles for each operating regime of the thruster.

Taking into account all above considerations and assumptions, the total ion current was estimated as $I_{i t}=\pi R^{2} \int_{-\theta_{\max }}^{\theta_{\max }}\left[J_{i}(\theta)-J_{i}\left(90^{\circ}\right)\right] \sin \theta d \theta$, where $J_{i}$ is the ion current density, $R$ is the distance from the probe to the thruster, $\theta$ is the probe angle relative to the physical centerline, $\theta_{\max } \approx 90^{\circ}$. Fig. 5 shows the current utilization, $I_{i t} / I_{d}$, and propellant utilization, $I_{i t} M_{i o n} / e \dot{m}$ efficiencies and the half plume angle estimated for $90 \%$ of the total ion flux. Here, $I_{d}$ is the discharge current density, $M_{i o n}$ is the ion mass, $\dot{m}$ is the anode mass flow rate and $e$ is electron charge. The deviation of these results, which was verified by repetition of the measurements several times during the same thruster runs, was less than $5 \%$.
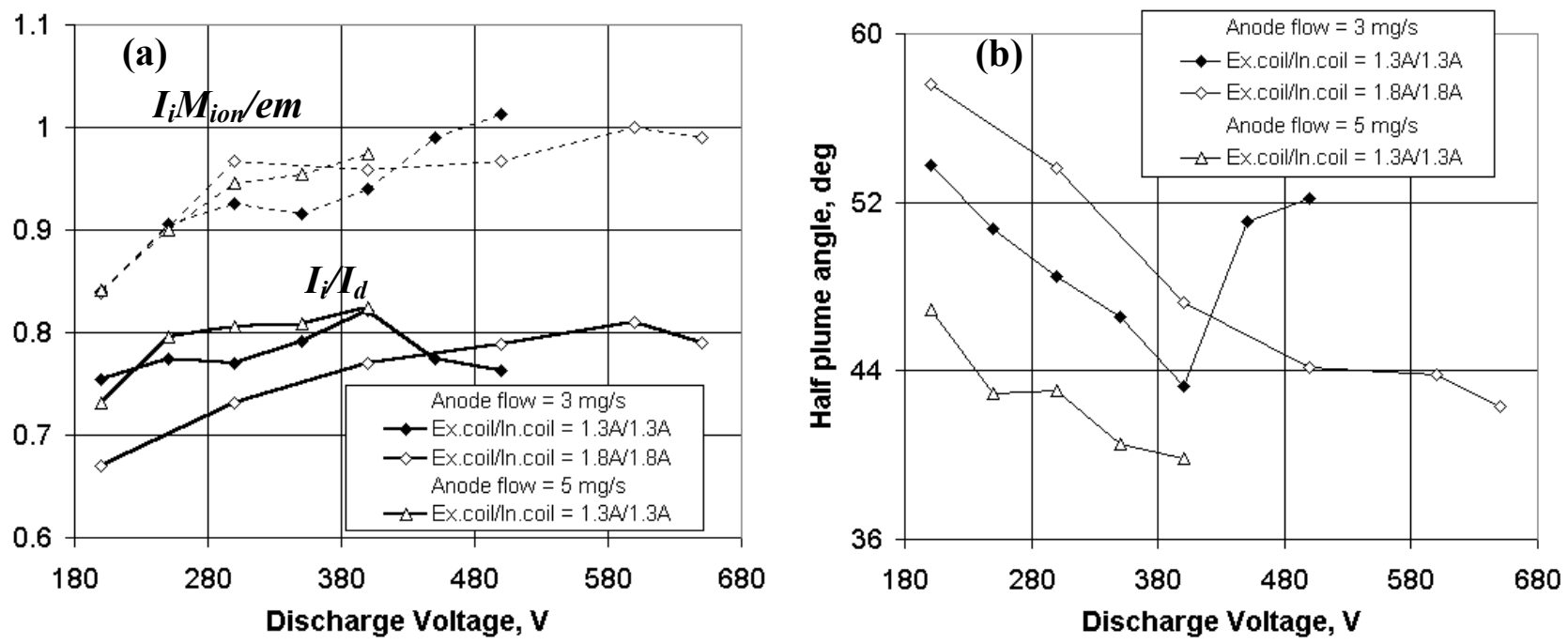

Fig. 5 Propellant and current utilization efficiencies (a) and the half plume angle for $90 \%$ of the total ion flux (b) deduced from the total ion flux measurements by a flat probe with a guarding sleeve. The measured ion flux includes all ions leaving the hemisphere limited by the radius of the probe rotation around the thruster $(730 \mathrm{~mm})$.

As can be seen in Fig. 5a, the current utilization for our thruster is 0.7-0.8 in the input power range of 0.5$1.8 \mathrm{~kW}$ (Fig.2). This is comparable with $\sim 0.8-0.9$ current utilization for 5kW NASA-173M thruster measured by researchers from Michigan ${ }^{12} \sim$ and for our smaller $1 \mathrm{~kW}$ Hall thruster ${ }^{13}$ (with design similar to the $2 \mathrm{~kW}$ version) $\sim 0.5-0.8$. These reference thrusters have demonstrated ability to operate with high anode efficiencies.

Note that the larger current utilization obtained for the NASA thruster might result from differences in the data treatment procedures. At large discharge voltages, the fraction of multi-charged ions might increase leading to higher propellant utilization. In this case, the axial electron current may also increase to sustain the enhanced ionization. This behavior can indeed be seen for large discharge voltage operating regimes at a mass flow rate of $3 \mathrm{mg} / \mathrm{s}$ and coils currents of $1.3 \mathrm{~A}$. On the other hand, a comparison of our results with more accurate retarding probe measurements of Ref. 11 for the state-of-the-art $4 \mathrm{~kW}$ Hall thruster $\left(I_{i} / I_{d} \sim 0.6\right)$ suggests that despite the fact that the measurement procedure was aimed to reduce the contribution of low energy ions, the probe with a guarding sleeve may still give overestimated current and propellant utilization efficiencies. In addition, the plume angle measurements are also sensitive to the presence of low energy and multi charged ions though, a narrowing of the plasma jet seen here at large discharge voltages was also reported in Ref.14. In general, these preliminary plume measurements are going to be repeated and verified with a retarding potential analyzer, currently being manufactured.

The miniaturized $45^{\circ}$ two-plate energy analyzer used in these experiments is shown in Fig. 6 . The principle of its operation is based on the deflection of charged particles in the uniform electric field between two parallel plates. The application of two plate energy analyzers for plume measurements in Hall thrusters is described elsewhere. ${ }^{11,15}$ The key difference of our analyzer is the small viewing angle, that imposes a visible area smaller than the overall thruster diameter and, therefore, may be used for spatial measurements of the ion energy distribution. Visible area can be changed by changing the input collimator. The analyzer has a flat 
geometry with a thickness of $25 \mathrm{~mm}$ to reduce its exposure to the plasma jet. Intermediate plates provide uniformity of the deflecting electric field. The base length between input and output holes is $93.5 \mathrm{~mm}$. Electrons are repelled by a tungsten grid. The deflected ions are collected by a Faraday cup. The plates and the cup are made from a carbon to minimize sputtering and secondary electron emission by energetic ions of xenon.

A multistage amplifier converts the Faraday cup current to voltage, filters out the high-frequency noise, and decouples the floating ground of the energy analyzer from the ground of the diagnostic system. The currentto-voltage conversion factor is $11 \mathrm{mV} / \mathrm{nA}$. The signal, together with the deflecting voltage, is recorded by National Instruments PCI MIO-64 input-output card. The analog output of the same I/O card controls the power supply to form a ramp of the deflecting voltage.

Energy resolution estimated from geometrical parameters of the energy analyzer is about $3 \%$. The actual energy resolution and sensitivity of the analyzer were verified in calibrating experiments using a $3 \mathrm{~cm}$ diameter commercially available gridded ion source. This source produces a quasineutral plasma beam with typically narrower energy spectrum of the accelerated ions than Hall thrusters. The calibration experiments took place in a small vacuum vessel. The ion source was operated with argon and xenon gases. The background pressure for xenon was between $(1-1.5) \cdot 10^{-5}$ torr. The ion energy was varied from $50 \mathrm{eV}$ to $500 \mathrm{eV}$. The gas flow rate and the distance between the ion source and analyzer were set to achieve a flux density comparable to that from the Hall thruster at a distance of $800 \mathrm{~mm}$.

Fig. 7 shows calibrating characteristics of the energy analyzer for xenon and argon gases. Measured energy spectra were fitted by Lornetzian distribution. The actual energy resolution, determined as a full width of half maximums (FWHM) of the spectra, was found about 3.5-4\% at ion energies higher than $120 \mathrm{eV}$. At lower ion energies FWHM was twice larger than the estimated analyzer resolution. This result may be partially attributed to the actual energy spread of the ion source at low beam voltages. In addition, facility effects ${ }^{5}$ might also cause this energy spread through charge exchange collisions between the low energy ion beam and background gas atoms in the small vacuum vessel.

For the thruster measurements, the analyzer was suspended on the supporting arm of the rotating system and pointed precisely towards the thruster center at the exit plane using a miniaturized adjustable (pitch, yaw and height) stage. The distance between the analyzer and the thruster center was $820 \mathrm{~mm}$.

Note that the visible area of the analyzer has an elliptical shape because of the focusing effect of the deflecting electric field at the plane of deflecting. Therefore, the length of the major elliptical axis is determined only by the input collimator. In the present experiments, we used two different collimators with the aperture of $\varnothing 1.5 \mathrm{~mm}$ and $\varnothing 2.5 \mathrm{~mm}$. The smaller aperture sets the major axis of the visible area to $54 \mathrm{~mm}$ that is less than the inner diameter of the channel $(73 \mathrm{~mm})$.

Fig. 8 shows preliminary results of the ion energy distribution measured at the thruster centerline with the $\varnothing 1.5 \mathrm{~mm}$ collimator. Here, the deflecting voltage is given relative to the cathode potential. For single charged ions, their kinetic energy is equal to the deflection voltage of the analyzer. For operating regimes at $250 \mathrm{~V}$ and $400 \mathrm{~V}$, the measured maximum ion energy was found about $30 \mathrm{eV}$ lower than the applied discharge voltage. This difference could be in principle explained by voltage potential drops near the anode and cathode, which might not contribute directly to the ion acceleration. However, at the discharge voltage of $500 \mathrm{~V}$ this difference disappear, and the measured maximum ion energy was about $500 \mathrm{~V}$. Taking into account that the energy analyzer was calibrated in the same energy range of xenon ions, this interesting behavior of the thruster may indicate on changes in the voltage potential distribution at higher discharge voltages, in particular, in the nearanode and near-cathode regions.

Another interesting observation is the presence of high-energy ions, which seem to be originating from the central part of the thruster (see Fig. 8). Indeed, as it was mentioned above, the visible area of the energy analyzer with $\varnothing 1.5 \mathrm{~mm}$ collimator is smaller than the inner diameter of the thruster channel. The clearly observable high energy pike was reproducible at different operating regimes. Note that there should be no significant voltage drop and ion production in this region of the thruster. Therefore, we did not expect high energy ions within the visible solid angle of the energy analyzer. On the other hand, ionization processes near the thruster exit and elastic collisions in the plume could produce low energy ions ${ }^{11}$, which were indeed seen in the measured spectra at $30^{\circ}$, but almost not at the centerline. These interesting phenomena of the presence of high energy ions and the depletion of low energy ions from the central part of the thruster at the exit plane are currently being studied in more details. 


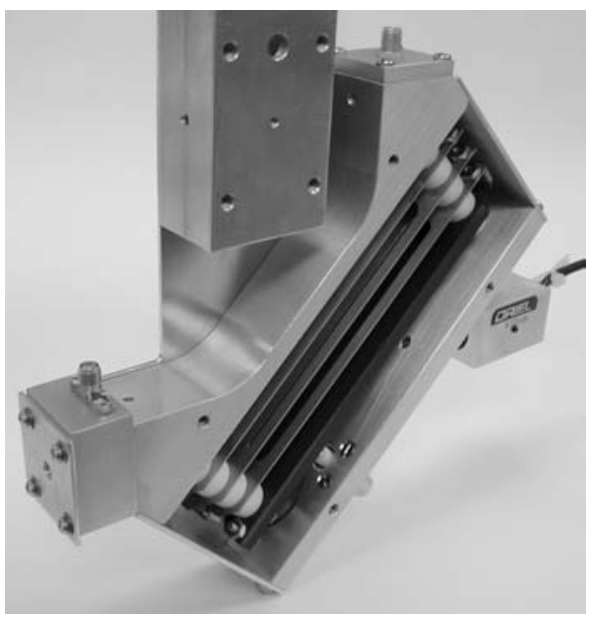

Fig. 6 Two plate energy analyzer for plume measurements.

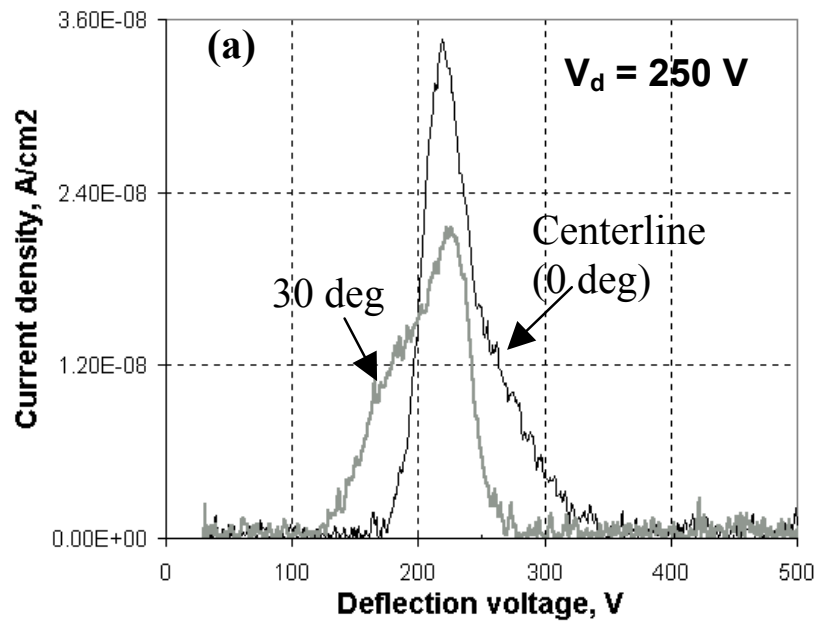

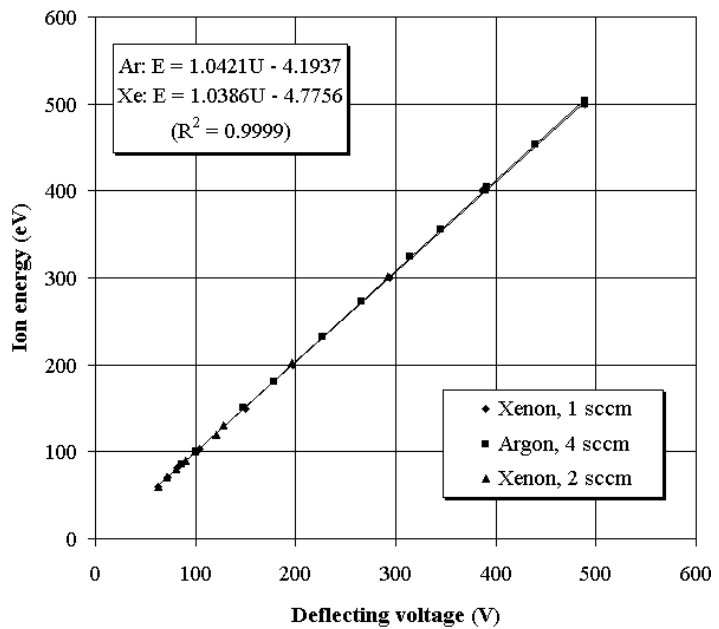

Fig. 7 Calibrating characteristics of the two plate energy analyzer.

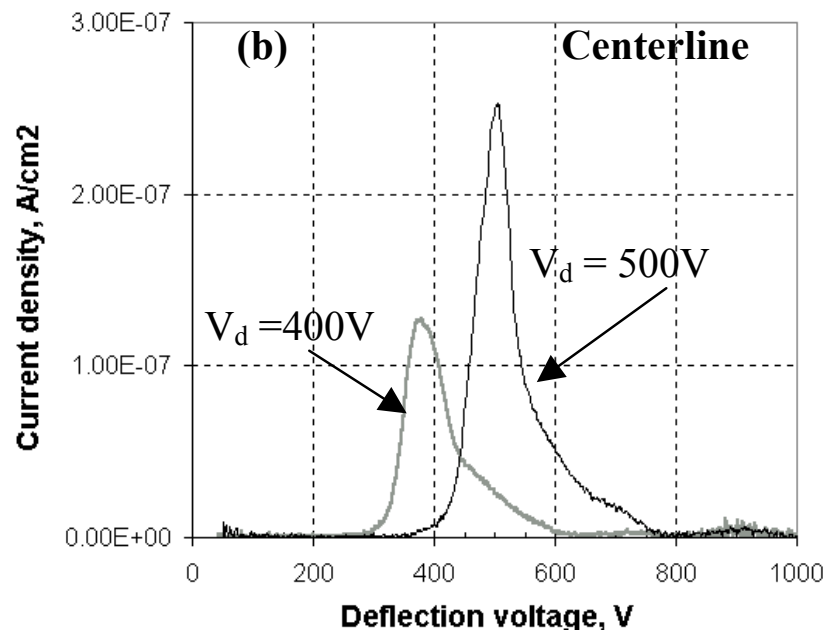

Fig. 8 Ion energy distribution measured for the thruster operating at the anode flow rate of $5 \mathrm{mg} / \mathrm{s}$ and the discharge voltages of $250 \mathrm{~V}$ (a), $400 \mathrm{~V}$ and $500 \mathrm{~V}$ (b) with the same magnetic field (inner and outer coils currents are equal $1.3 \mathrm{~A}$ ) by two-plate energy analyzer at the centerline and $30 \mathrm{deg}$ from the centerline.

\section{Measurements inside the channel}

The upgraded probe diagnostics include fast and slow movable probe setup, which are mounted on two separate aluminum breadboards placed on opposite sides of the thruster table (Fig. 9). In addition, several stationary cylindrical probes are placed at different locations in the thruster channel.

The fast movable probe is introduced into the thruster axially through the channel exit. On its way in and out of the channel, the probe passes through the acceleration and ionization regions and therefore, may induce plasma perturbations. ${ }^{16}$ In order to reduce perturbations, the new probe design, which was suggested in Ref. 16, has a shield made from a low secondary electron emission material.

In the present configuration, the probe consists of a $1.1 \mathrm{~mm}$ OD diameter double bore tube, which is made from a high purity alumina ceramic material. This ceramic tube is inserted in a molybdenum shield tube of a 1.7 $\mathrm{mm}$ OD diameter and $0.14 \mathrm{~mm}$ wall thickness. A $0.25 \mathrm{~mm}$ thoriated tungsten wire is etched at the tip of the filament to approximately $0.1 \mathrm{~mm}$ diameter. The wire is inserted into the bores of the alumina tube and connected at the back to 16 AWG shielded twisted-pair Teflon insulated cable. The cable is connected to a SHV electrical feed-through, which is from airside connected to a dc heating power supply. The floating potential of the emissive probe is measured by 100:1 divider (500 MOhm:5 MOhm) connected to a high input impedance isolation amplifier. 
The probe with electrical connections and wires is assembled on an aluminum probe arm (Fig. 9), which is fixed on a compact Newport optical stage. This stage provides manual alignment of pitch, yaw and height of the probe relative to the thruster axis. The stage is mounted on the traveling platform of the fast positioner, which moves the probe in the axial direction along the thruster axis (Fig. 9). The fast positioner is a SR model linear positioning stage by H2W Technologies equipped with a linear encoder and feedback control by a Galil 1820 programmable motion controller connected to the control and data acquisition system. The travel distance of this stage is about $500 \mathrm{~mm}$, the encoder resolution is $0.01 \mathrm{~mm}$, and the maximum speed is $1500 \mathrm{~mm} / \mathrm{s}$. The linear motor is capable of up to $12 \mathrm{~g}$ 's acceleration with a maximum load of $3 \mathrm{Kg}$. In general, the fast positioner demonstrated reliable operation under harsh environments during the thruster operation, while carrying asymmetrically distributed loads (probe supports, alignment stages, etc). The probe setup parts (probe arm, fast positioner) exposed to the plasma are covered with carbon velvet plates to protect them from sputtering.

The fast positioner is rigidly mounted on a X-Y movable table (Fig. 9) consisting of two motorized Velmex linear positioning stages and two $5 \mu \mathrm{m}$-resolution Renishaw optical encoders. These slow movable stages can change the probe position in the radial direction moving it across the channel and/or in the axial direction, placing it behind the thruster in order to hide the probe setup from interacting with the plasma jet, while not in use. For compensation of possible torques developed during acceleration of the fast positioner, the traveling base of each Velmex positioner is connected to a linear bushing made from low friction Textron plates fixed in an aluminum frame.

Fig. 10 shows illustrative (smoothed) results of discharge current perturbations induced by the fast probe of two different designs, unshielded alumina ceramic tube and shielded with the molybdenum tube. As can be seen, the shielded probe induces smaller perturbations than the conventional unshielded probe. Furthermore, at some operating regimes of the thruster we observed almost no plasma perturbations with shielded probes. However, it is not clear yet if this result is due to the shielded design of the probe or to the magnetic field distribution, which was different in these regimes.

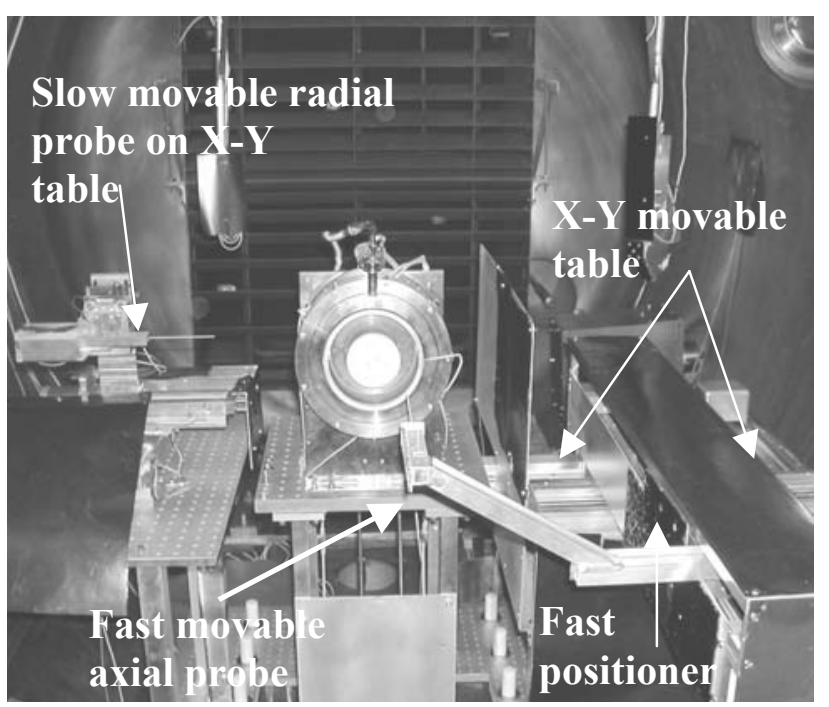

Fig. 9 Fast and slow movable probe setup for plasma measurements inside the thruster.

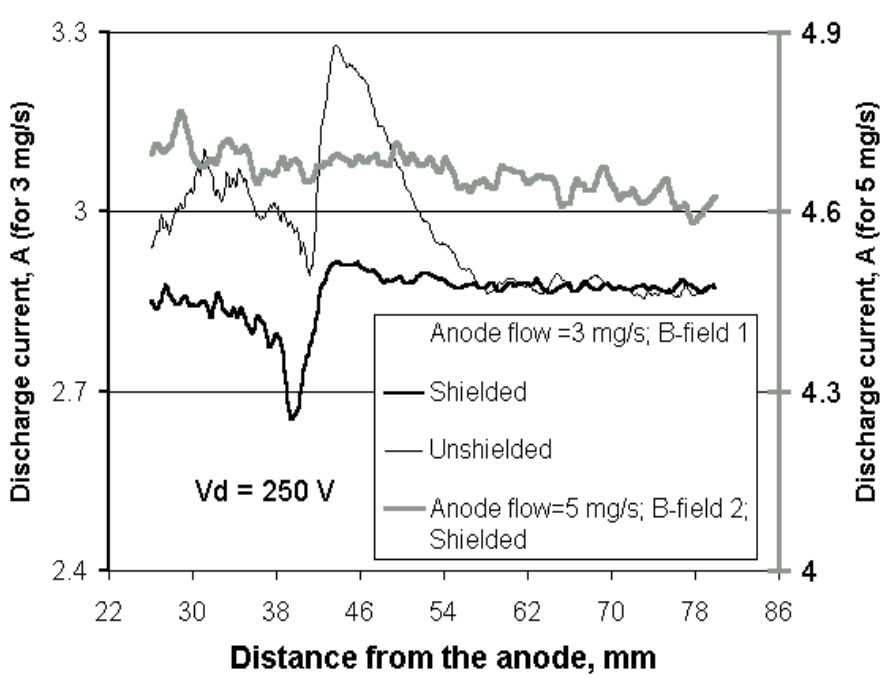

Fig. 10 Discharge current perturbations induced by the fast probe of two different designs: unshielded and shielded. The thruster exit is at $46 \mathrm{~mm}$.

Position measurements of the movable setup and data acquisition from emissive and stationary probes were performed using a National Instruments PCI-6071E board (max sample rate for input signal 1.25/sec). For the fast probe experiments the data acquisition was configured to measure the counter position, discharge current, stationary and movable probe potentials relative to the ground, heating current and heating voltage of the emissive probe, cathode potential relative to the ground, and other relevant analog inputs at $11 \mathrm{kHz}$ acquisition rate when triggered by a digital signal from the fast positioner controller at the beginning of motion. The output signal of high impedance dividers used to measure the probe voltage, was buffered through a LF356 op-amp to ensure fast amplifier settling times on the data acquisition board. 
The floating potential and plasma potential distributions measured by cold and hot emissive probe, respectively, along the channel median at discharge voltage of $250 \mathrm{~V}$ and mass flow rate of $3 \mathrm{mg} / \mathrm{s}$ are shown in Fig. 11. The procedure of the emissive probe measurements was similar to that described in Refs. 3,7. However, the heating of the filament was applied only for a short period $(\sim 1 \mathrm{~min})$ in order to avoid overheating of the molybdenum shield. Overheating might cause arcing and, as a result, shortening between the shield and the probe. In order to prevent the shortening, a segmented shield probe is currently being developed and tested.

Fig. $11 \mathrm{~b}$ shows the electric field and the electron temperature deduced from the probe measurements. The electric field was estimated from the plasma potential measurements. The electron temperature was derived from cold floating and emissive probe measurements. Here, for simplicity of data analysis, we neglected a contribution of supersonic ions from the plasma to the total flux collected by the cold probe to maintain its floating potential.

It is worth to mention some interesting features of these results: (1) a significant fraction of the voltage potential drop is outside the thruster (Fig. 11a); (2) there is a minimum in the floating potential profile, outside the thruster in the vicinity of the magnetic field lines, which intersect the cathode and the median plane at the channel exit (Figs. 1, 11a); and (3) increased electron temperature and the electric field in the same region as the minimum (Fig. 11b). The first can probably be attributed to the wide channel $(25 \mathrm{~mm})$ with substantial fringing magnetic field. Note that the placement of the acceleration region in the defocusing field almost did not affect the plume angles (a half angle in this regime $\sim 50^{\circ}$, see also Fig. 5) as compared to those measured for the $1 \mathrm{~kW}$ Hall thruster with an $18 \mathrm{~mm}$ wide channel in the same discharge voltage range. ${ }^{6}$
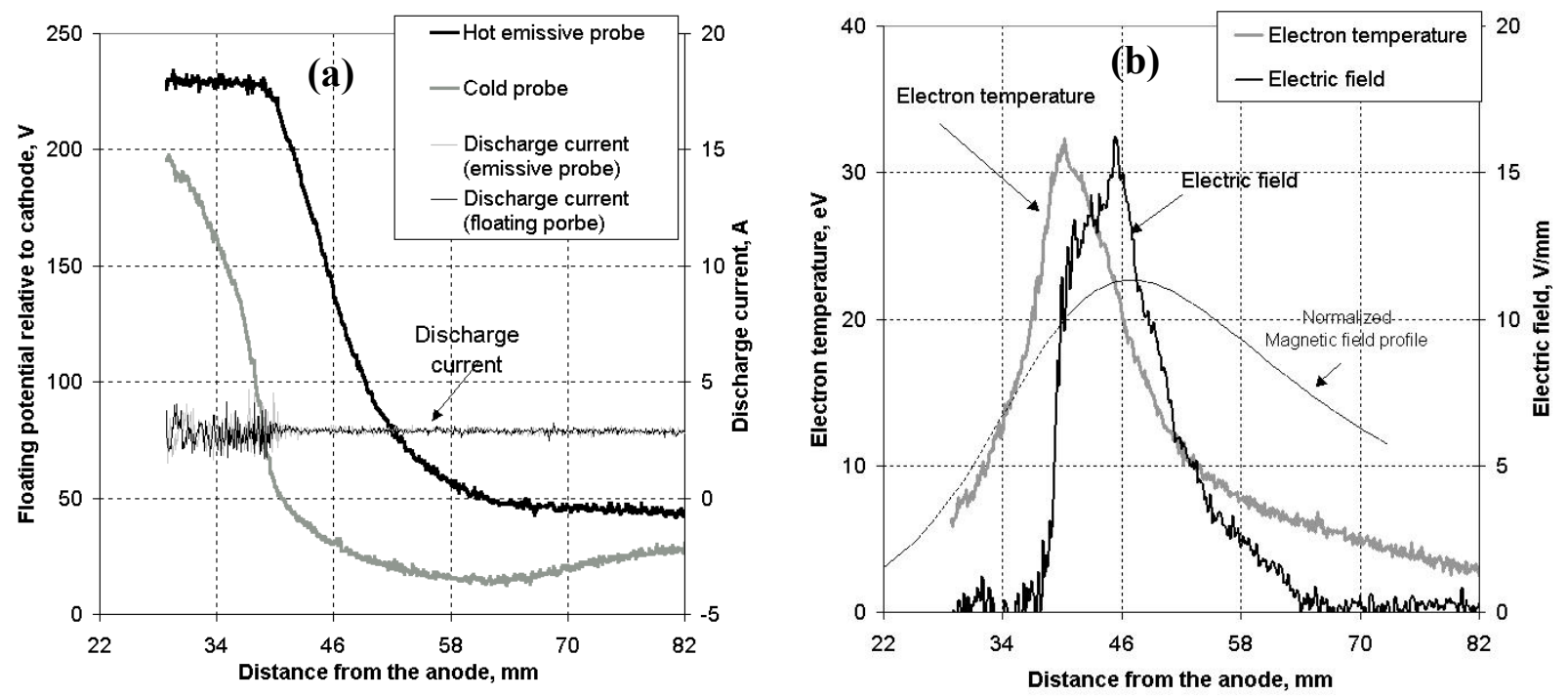

Fig. 11. Floating potentials (a) measured by cold and hot emissive probe (taken as the plasma potential) along the thruster median. The thruster exit is $46 \mathrm{~mm}$. The discharge voltage and mass flow rate are $250 \mathrm{~V}$ and $3 \mathrm{mg} / \mathrm{s}$, respectively. The actual plasma potential is $\sim T_{e}$ larger than the floating potential of the emissive probe due to double sheath effects. Electric field and electron temperature (b) deduced from the probe measurements. The radial magnetic field is simulated for the thruster operating regime with external and internal coils currents equal 1A. The maximum magnetic field is 90 Gauss.

Interestingly, there is a minimum of the floating potential at $\sim 1.5 \mathrm{~cm}$ from the thruster exit (Fig. 11a). It is not clear at the moment if this minimum outside the thruster reflects solely changes of the electron temperature or is affected by, for example, energetic electrons from the cathode. The cathode, which is placed at $60^{\circ}$ to the thruster axis, injects electrons to the magnetic field lines, some of which intersect the median plan in the vicinity of the floating potential minimum (Fig. 11a). According to Ref. 17, these electrons form an energetic beam with a velocity component along the magnetic field. If this is the case and since there also exist lower energy electrons of the plasma bulk, then the estimated electron temperature does not represent the actual electron temperature in this region. In general, this interesting behavior of plasma parameters outside the thruster channel needs more detailed studies. 


\section{SUMMARY}

In this paper, we described our upgraded experimental setup for studies of the segmented electrode Hall thrusters. The vacuum facility includes cryogenic pumps. A new $2 \mathrm{~kW}$ Hall thruster was operated and parametrically characterized in the power range of $0.5 \mathrm{~kW}$ to $3.5 \mathrm{~kW}$. Measurements of the total ion flux from the thruster showed that this thruster can achieve propellant and current utilization efficiencies of $\sim 0.9-1$ and 0.7 0.8 , respectively, which are comparable with existing high performance Hall thrusters.

A $45^{\circ}$ two-plate energy analyzer with a narrow visible angle was developed, calibrated and successfully tested. With the diameter of visible area almost twice smaller than the inner diameter of the thruster channel, we measured high energy ions at the thruster centerline, in the discharge voltage range of 250-600 V.

A new fast movable probe setup for plasma measurements inside the channel uses a shielded probe design to reduce probe-induced perturbations of the plasma. Somewhat more than $60 \%$ of the voltage potential drop was measured outside the thruster channel in the defocusing fringing field. The electron temperature increases in this region to $20 \mathrm{eV}$, but its values deduced from floating emissive and cold probe measurements may be overestimated if there is an energetic electron beam from the cathode, which we might observe.

In addition, a slow movable probe setup for accurate measurements in the near anode region was developed (Fig. 9). While moving inside the thruster channel, probe-induced perturbations of the plasma were negligible, which allows plasma measurements in the discharge voltage range of 200-700 V. This probe setup is described in Ref. 18.

\section{ACKNOWLEDGEMENT}

The authors are grateful to Richard Yager, Victor Garzotto, George Rose, Laszlo Varga, Glenn Atkinson, William Dix and Garry D'Amico for their technical support in the upgrade of the experimental setup. We wish to thank also Mr. Artem Smirnov for fruitful discussions of experimental results and assistance in preparations for experiments. Dr. Timothy Knoweles from Energy Science Laboratory Inc. provided us with carbon velvet samples.

This work was supported by grants from New Jersey State Commission on Science and Technology and U.S. Department of Energy under Contract No. DE-AC02-76-CHO3073.

\section{REFERENCES}

${ }^{1}$ A. I. Morozov and V. V. Savelyev, in Review of Plasma Phsyics, edited by B.B. Kadomtsev and V. D. Shafranov, Consultants Bureau, New York, 2000, Vol. 21, p. 223.

${ }^{2}$ A. Fruchtman and N. J. Fisch, AIAA paper 99-2142, Los Angeles, CA, June 1999.

${ }^{3}$ Y. Raitses, D. Staack and N. J. Fisch, AIAA paper-2002-3594, Indianapolis, In. July 2002.

${ }^{4}$ D. H. Manzella, R. S. Jankovsky and R. R. Hofer, AIAA paper 2002-3676, Indianapolis, IN, July 2002.

${ }^{5}$ Hofer, R. R., Gallimore, A. D., AIAA paper-2002-4111, Indianapolis, IN, July 7-10, 2002.

${ }^{6}$ N. J. Fisch, Y. Raitses, L. A. Dorf and A. A. Litvak, J. Appl. Phys. 89, 2040, 2001.

${ }^{7}$ Y. Raitses, M. Keidar, D. Staack and N. J. Fisch, J. Appl. Phys., 92, 4906, 2002.

${ }^{8}$ T. Randolph, V. Kim, H. Kaufman, K. Kozubsky, K. Zhurin and M. Day, Paper-93-93, the $23^{\text {rd }}$ IEPC

Conference, Seattle, WA, Sept. 1993.

${ }^{9}$ D. Staack, Y. Raitses and N. J. Fisch, Paper 03-0273, the $28^{\text {th }}$ IEPC conference, Toulouse, France, March 2003.

${ }^{10}$ S. Barral, K. Makowski, and Z. Peradzynski, N. Gascon, M. Dudeck, AIAA 2002-4245, Indianapolis IN.

${ }^{11}$ J. E. Pollard, K. D. Diamant, V. Khaims, L. Wethman, D. Q. King and K. H. de Grys, AIAA paper 2001-3351, Slat-Lake City UT, July 2001.

${ }^{12}$ Walker, M. L. R., Hofer, R. R., Gallimore, A. D, AIAA paper-2002-4253, Indianapolis, IN, July 7-10, 2002.

${ }^{13}$ N. J. Fisch, Y. Raitses, L. A. Dorf and A. A. Litvak, AIAA paper 99-2572, Los Angeles, CA, June 1999.

${ }^{14}$ B. S. Borisov, K. K. Mikhaylov, A. V. Rusakov, A. V. Semenkin and H. O. Chislov, IEPC-95-51, the $24^{\text {th }}$ IEPC conference, Moscow, Sept. 1995.

${ }^{15}$ L. B. King and A. D. Gallimore, AIAA paper-96-2712, Lake Buena Vista, FL, July 1996.

${ }^{16}$ D. Staack, Y. Raitses and N. J. Fisch, AIAA paper 2002-4109, Indianapolis, IN, July 2002

${ }^{17}$ V. Yu. Fedotov, A. A. Ivanov, G. Guerrini, A. N. Vesselovzorov and M. Bacal, Phys. Plasmas, 6, 4360, 1999.

${ }^{18}$ L. Dorf and Y. Raitses, IEPC paper 03-0157, the $28^{\text {th }}$ IEPC conference, Toulouse, France, March 2003. 


\section{External Distribution}

Plasma Research Laboratory, Australian National University, Australia

Professor I.R. Jones, Flinders University, Australia

Professor João Canalle, Instituto de Fisica DEQ/IF - UERJ, Brazil

Mr. Gerson O. Ludwig, Instituto Nacional de Pesquisas, Brazil

Dr. P.H. Sakanaka, Instituto Fisica, Brazil

The Librarian, Culham Laboratory, England

Mrs. S.A. Hutchinson, JET Library, England

Professor M.N. Bussac, Ecole Polytechnique, France

Librarian, Max-Planck-Institut für Plasmaphysik, Germany

Jolan Moldvai, Reports Library, MTA KFKI-ATKI, Hungary

Dr. P. Kaw, Institute for Plasma Research, India

Ms. P.J. Pathak, Librarian, Insitute for Plasma Research, India

Ms. Clelia De Palo, Associazione EURATOM-ENEA, Italy

Dr. G. Grosso, Instituto di Fisica del Plasma, Italy

Librarian, Naka Fusion Research Establishment, JAERI, Japan

Library, Plasma Physics Laboratory, Kyoto University, Japan

Research Information Center, National Institute for Fusion Science, Japan

Dr. O. Mitarai, Kyushu Tokai University, Japan

Dr. Jiangang Li, Institute of Plasma Physics, Chinese Academy of Sciences, People's Republic of China

Professor Yuping Huo, School of Physical Science and Technology, People's Republic of China

Library, Academia Sinica, Institute of Plasma Physics, People's Republic of China

Librarian, Institute of Physics, Chinese Academy of Sciences, People's Republic of China

Dr. S. Mirnov, TRINITI, Troitsk, Russian Federation, Russia

Dr. V.S. Strelkov, Kurchatov Institute, Russian Federation, Russia

Professor Peter Lukac, Katedra Fyziky Plazmy MFF UK, Mlynska dolina F-2, Komenskeho Univerzita, SK-842 15 Bratislava, Slovakia

Dr. G.S. Lee, Korea Basic Science Institute, South Korea

Institute for Plasma Research, University of Maryland, USA

Librarian, Fusion Energy Division, Oak Ridge National Laboratory, USA

Librarian, Institute of Fusion Studies, University of Texas, USA

Librarian, Magnetic Fusion Program, Lawrence Livermore National Laboratory, USA

Library, General Atomics, USA

Plasma Physics Group, Fusion Energy Research Program, University of California at San Diego, USA

Plasma Physics Library, Columbia University, USA

Alkesh Punjabi, Center for Fusion Research and Training, Hampton University, USA

Dr. W.M. Stacey, Fusion Research Center, Georgia Institute of Technology, USA

Dr. John Willis, U.S. Department of Energy, Office of Fusion Energy Sciences, USA

Mr. Paul H. Wright, Indianapolis, Indiana, USA 
The Princeton Plasma Physics Laboratory is operated by Princeton University under contract with the U.S. Department of Energy.

\author{
Information Services \\ Princeton Plasma Physics Laboratory \\ P.O. Box 451 \\ Princeton, NJ 08543
}

Phone: 609-243-2750

Fax: 609-243-2751

e-mail: pppl_info@pppl.gov

Internet Address: http://www.pppl.gov 